\title{
Static and Dynamic Buckling of Rectangular Functionally Graded Plates Subjected to Thermal Loading
}

\author{
L. Czechowski ${ }^{1}$ and K. Kowal-Michalska ${ }^{2}$ \\ Lodz University of Technology, Lodz, Poland \\ ${ }^{1}$ leszek.czechowski@p.lodz.pl \\ ${ }^{2}$ katarzyna.kowal-michalska@p.lodz.pl
}

уДК 539.4

\section{Статическая и динамическая потеря устойчивости прямоугольных функционально-градиентных пластин, подверженных тепловой нагрузке}

\section{Л. Чеховски, К. Коваль-Михальска}

Лодзинский технический университет, Лодзь, Польша

\begin{abstract}
Представлено явление потери устойчивости при статической и динамической нагрузке (импульс конечной длительности) функционально-градиентных пластин, подверженных воздействию равномерного повышения температуры. Рассмотрены шарнирно опертые или закрепленные (вдоль кромок) тонкие прямоугольные пластины с неподвижными кромками. Предполагается, что свойства материала, плавно изменяющиеся по толщине, не зависят от температуры. Проведены исследования для разных значений коэффициента относительного объема и равномерного приращения температуры, представленного в виде прямоугольного импульса конечной длительности.
\end{abstract}

Ключевые слова: динамическое выпучивание, функционально-градиентные пластины, тепловая нагрузка.

Introduction. Known since 1984 functionally graded materials (FGM) very soon became popular in scientific research and engineering applications. Typical FGM is an inhomogeneous composite made up of two constituents - typically of metallic and ceramic phases which relative content changes gradually across the thickness of a plate or a shell. This eliminates the adverse effects between the layers (e.g., shear stress concentrations and/or thermal stress concentrations), typical for layered composites. The high-resistance heat capacity of ceramic and good mechanical properties of metal phase make that the leading application area of FGM structures are high-temperature environments (spacecraft, nuclear reactors or structures for the chemical industry and defence) $[1,2]$.

Nonlinear analysis of plates and shells devoted to basic types of loads is covered in Shen monograph [2]. He considered static bending and thermal bending as an introduction to buckling and postbuckling behaviour of FGM plates and shells. The shear deformation effect is employed in the framework of Reddy's higher order shear deformation theory (HSDT). 
In [1], alongside HSDT for FGM plates Reddy presents the comparison of first order shear deformation theory (FSDT) and classical laminate plate (CLPT) theory application for functionally graded plates. According to presented results it is obvious that for thin plates the application of FSDT gives results in practice the same as HSDT. The discrepancy between both theories is of $2 \%$ in calculated deflections of analyzed plates.

The static buckling problem of functionally graded plates is discussed in the frame of different approaches, e.g., in [3-5] - biaxial in-plane compression and thermal loads (constant temperature) with axial compression, in $[6,7]-$ biaxial in-plane compression, in [8] - for thermal stresses only, and in [9] - for different temperature distribution through the plate thickness.

In mentioned above publications the dominant subject are the static mechanical or steady-state thermal loadings. The dynamic types of analyses concern mostly the vibrations problems, e.g., [10]. From authors previous experience connected with static and dynamic analysis of thin-walled isotropic and orthotropic composite plates and columns, e.g., $[11,12]$ the dynamic buckling of thin-walled structure is a theoretically difficult problem but of great importance for practical engineering applications.

It is well known that for pulse loads of short duration the structure can withstand the dynamic loading magnitude much greater than the static one. The dynamic pulse buckling occurs for pulses of intermediate amplitude and duration close to the period of fundamental natural flexural vibration. In such case the effects of damping are neglected. It should be remembered that opposite to the static loading, the dynamic buckling only occurs for imperfect structure, the bifurcational dynamic buckling load does not exist. Therefore, it is necessary to define this 'critical' load on the basis of an assumed dynamic buckling criterion. In most publications the Budiansky-Hutchinson criterion [13] is applied to determine the dynamic critical load - it means the amplitude of pulse load which at given duration causes the dynamic buckling.

Dynamic buckling criterion of Budiansky-Hutchinson states that: dynamic stability loss occurs, when the maximal plate deflection grows rapidly with the small variation of the load amplitude.

Therefore, similarly to the mechanical loading, the parameter $D L F$ is introduced as a quotient of pulse amplitude of temperature increment to the static critical temperature rise:

$$
D L F=\Delta T^{d y n} / \Delta T_{c r}^{s t}
$$

The critical value of dynamic load factor $D L F_{c r}$ is determined on the basis of the assumed criterion and then the critical value of dynamically applied temperature increment $\Delta T_{c r}^{d y n}$ can be found.

In previous works [14, [15] static and dynamic buckling analysis was presented for FG rectangular simply supported plates under mechanical (uniform compression) and thermomechanical loading. In this paper the dynamic response of thin FG rectangular plates, subjected to an uniform temperature rise in form of an rectangular pulse of finite duration is analysed basing on the finite element method (ANSYS software). 
1. Modeling of Material Properties. The studied plates have continuously varying material properties only in the thickness direction. On the top surface of a plate, pure metal is assumed, grading finally to the bottom surface containing pure ceramics. The volume fractions of metal $V_{m}$ and ceramics $V_{c}$ can be written accordingly to the simple power law distribution:

$$
\begin{aligned}
& V_{m}(z)=\left(1-\frac{z}{h}\right)^{n}, \\
& V_{c}(z)=1-V_{m}(z),
\end{aligned}
$$

where $0 \leq z \leq h, n$ denotes the volume fraction index across the plate thickness $h$ $(n \in<0, \infty)$, for $n=0$ plate is metallic and for $n=\infty$ is ceramic.

Figure 1 presents the distribution of volume fraction of ceramic and metal components across the plate thickness for different values of index $n$.

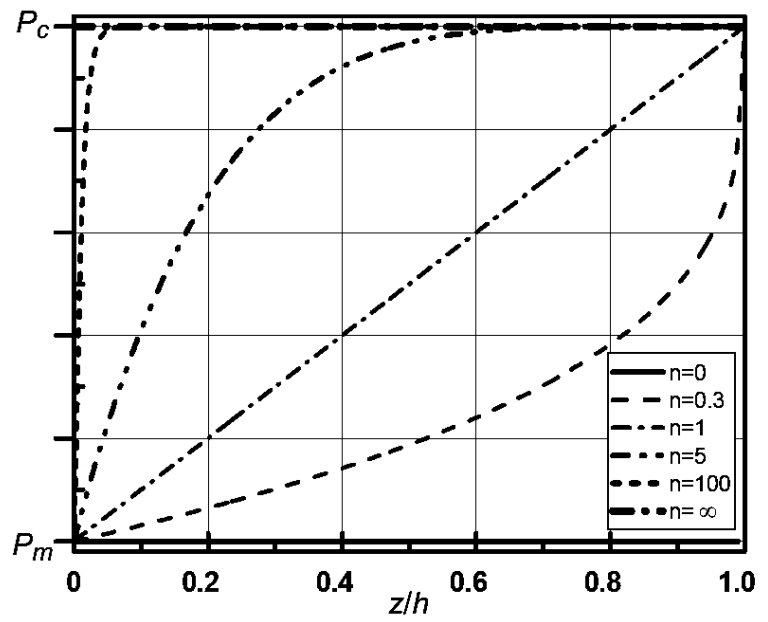

Fig. 1. Volume fraction of ceramics and metal dependent on the distribution index across plate thickness.

According to the law of mixtures, the effective material properties $P_{\text {eff }}$ (it means: $\rho$ is density, $\alpha$ is coefficient of thermal expansion, $E$ is the Young modulus, and $v$ is Poisson's ratio), are obtained in a form

$$
P_{e f f}(z)=P_{m} V_{m}(z)+P_{c} V_{c}(z)=P_{c}+\left(P_{m}-P_{c}\right)\left(1-\frac{z}{h}\right)^{n},
$$

where $P_{c}$ i $P_{m}$ denote material properties of ceramics and metal, respectively, assumed as temperature independent.

2. Subject of Consideration. Thin, rectangular plates made of functionally graded material were considered. Two different boundary conditions were taken into account: all edges clamped and all edges simply supported. In both cases the edges are immovable (see Table 1). 
$\mathrm{T}$ a b 1 e 1

Boundary Conditions of Plates

\begin{tabular}{|c|c||}
\hline Clamped plate & Simply supported plate \\
\hline Edge $1,2,3,4:$ & $\begin{array}{l}\text { Edge } 1,3: u_{x}, u_{z}=0 \\
\text { Edge } 2,4: u_{y}, u_{z}=0\end{array}$ \\
\hline$u_{x}, u_{y}, u_{z}, \operatorname{rot}_{x}, \operatorname{rot}_{y}, \operatorname{rot}_{z}=0$ & Edge 3 \\
\hline
\end{tabular}

An uniform temperature rise through the whole plate and continuously varying material properties across the plate thickness related to the power law distribution were assumed in the investigations. When dynamic buckling is investigated, the temperature increment is applied in form of rectangular pulse of value $\Delta T^{d y n}$ and duration time $t_{p}$.

3. Numerical Model. The numerical simulations and appropriate calculations have been conducted using the finite element method (ANSYS14.0).

The numerical models assigned for study were divided into SHELL132 and SHELL281 type elements [16] (Fig. 2). SHELL132 has eight nodes with up to 32 temperature degrees of freedom at each node and is applicable to a 3D steady-state or transient thermal analysis. SHELL281 has also eight nodes with six degrees of freedom at each node and includes the effects of transverse shear deformation. This applied element is well-suited for linear, high-rotation or high-strain nonlinear applications and moderately thick shell structures. In addition, SHELL281 element is very useful for multilayered applications to model laminated composite shells or sandwich structures what in case of functionally graded materials across the thickness is very profitable.

A shell element containing 20-layers with various material properties was considered. For a determination of large deflections of structures the GreenLagrange nonlinear-displacement equation was employed. Calculations were incrementally performed using the Newton-Raphson convergence approximation method. The time step in applied Newmark time integration procedure has been taken as 1/50 of the period of plate fundamental natural vibration.

Numerical simulation was carried out in two stages. In the first stage it was essential to determine static critical temperature rise and corresponding buckling mode and also a frequency of fundamental flexural natural vibrations for each structure according to assumed distribution of material properties and boundary conditions. Next, calculations in incremental solution for large strains taking into account the pulse duration corresponding to period of natural flexural vibrations of a given structure were performed. For all considered structures the initial deflection corresponding to the first buckling mode of amplitude has $w_{0}=0.01 \mathrm{~h}$ been taken into account. The observation of structures behavior was continued in time two times longer than the pulse duration. 


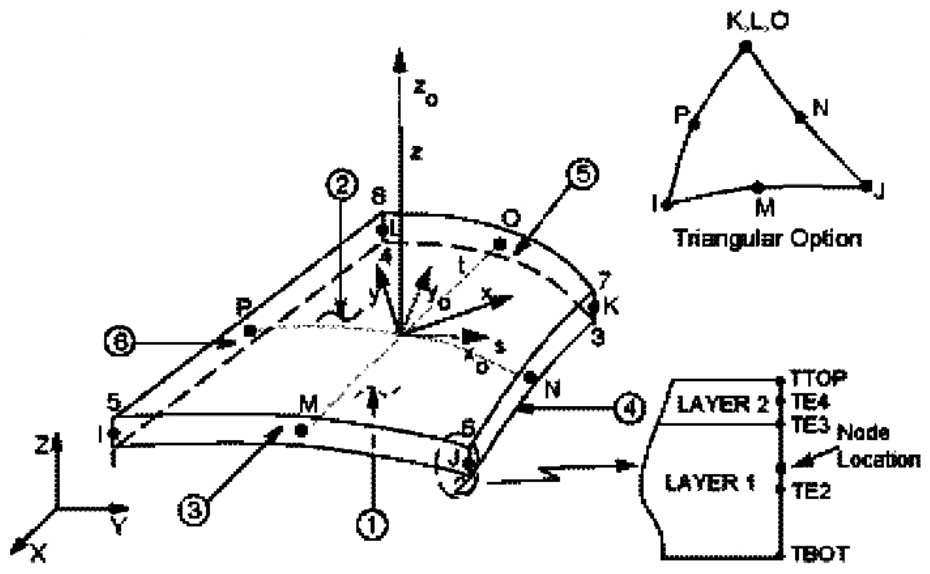

a

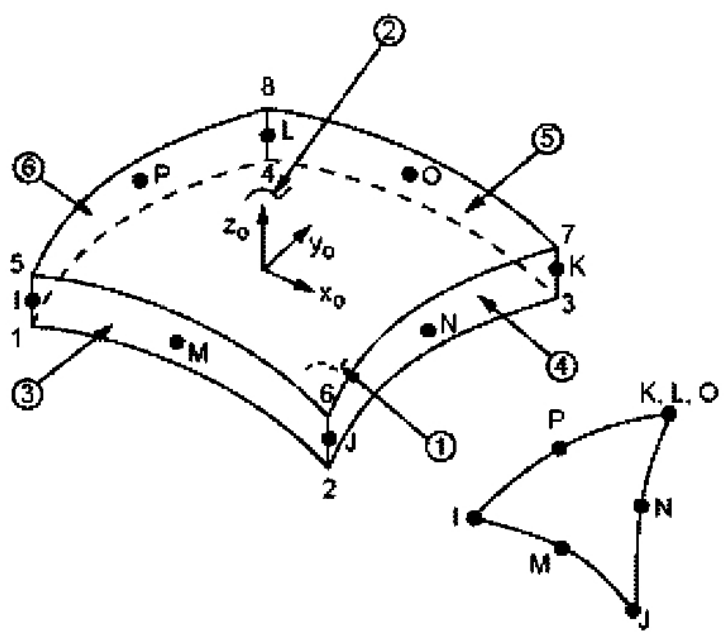

b

Fig. 2. Types of applied elements with 8 nodes: Shell132 (a) and Shell281 (b).

4. Results of Numerical Calculations. The calculations were performed for FG square plates of ratio width to thickness $a / h=100$. The material properties of components were assumed as shown in Table 2. The duration $t_{p}$ of the temperature pulse was equal to one or one half of period of natural flexural vibrations $t_{0}$ of considered structure with regard to boundary conditions and material properties distribution across the plate thickness (see Table 3).

The results of calculations have been presented in diagrams as the relation between non dimensional maximal deflection $(w / h)$ and the applied temperature increment (statically $\Delta T^{s t}$ or as a pulse loading $\Delta T^{d y n}$ ) and additionally as the relation $w / h$ versus $D L F$.

In aim to compare the correctness of the applied model the results obtained in static case have been compared with the results known from the literature [9]. The very good agreement has been achieved for the critical values of temperature rise $D T_{c r}^{s t}$ and also for postbuckling behavior (exemplary curves are shown in Fig. 3). 
$\mathrm{T}$ a b 1 e 2

Material Properties of Constituents

\begin{tabular}{||c|c|c|}
\hline \multicolumn{1}{|c|}{ Properties } & $\mathrm{Al}_{2} \mathrm{O}_{3}$ & $\mathrm{Ni}$ \\
\hline Young's modulus $E, \mathrm{GPa}$ & 393 & 200 \\
\hline Thermal expansion coefficient $\alpha, \mathrm{K}^{-1}$ & $13.3 \cdot 10^{-6}$ & $8.8 \cdot 10^{-6}$ \\
\hline Poisson's ratio $v$ & 0.25 & 0.3 \\
\hline Density $\rho, \mathrm{kg} / \mathrm{m}^{3}$ & 2000 & 7800 \\
\hline
\end{tabular}

T a b 1 e 3

Periods of Natural Flexural Vibrations $t_{0}(\mathrm{~ms})$

\begin{tabular}{|c|c|c|}
\hline Volume fraction index $n$ & Clamped plate & Simply supported plate \\
\hline 0 & 11.20 & 20.80 \\
\hline 0.3 & 9.19 & 17.07 \\
\hline 1.0 & 7.62 & 13.80 \\
\hline 5.0 & 5.50 & 11.04 \\
\hline$\infty$ & 4.18 & 7.65 \\
\hline
\end{tabular}

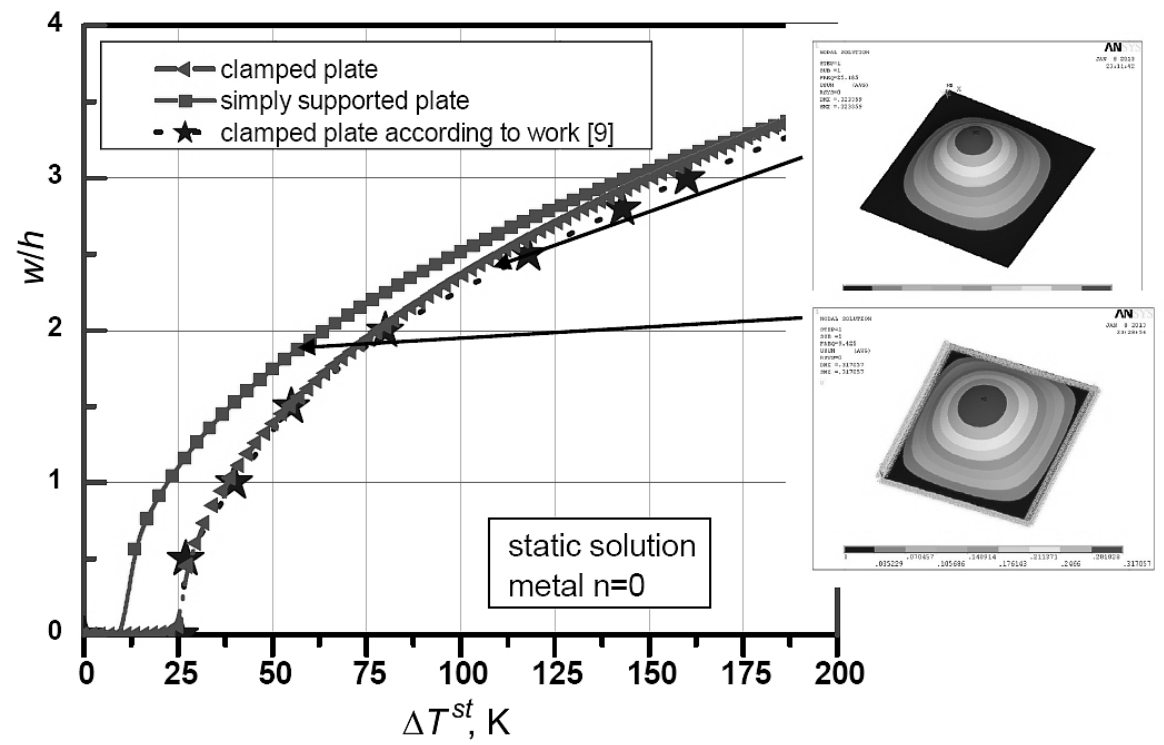

Fig. 3. Static post buckling curves for metal plates subjected to uniform temperature rise and corresponding buckling modes.

The results of numerical calculations for chosen values of volume fraction index $n$ and two values of pulse duration of temperature increment have been shown in Figs. 4 and 5 for plates with clamped edges and in Figs. 6 and 7 for plates simply supported along all edges. Static and dynamic critical values of temperature increment have been collected in Table 4 (for pulse duration equal to the period of natural flexural vibrations $t_{p}=t_{0}$ ) and in Table 5 (for pulse duration equal to the period of natural flexural vibrations $\left.t_{p}=0.5 t_{0}\right)$. 


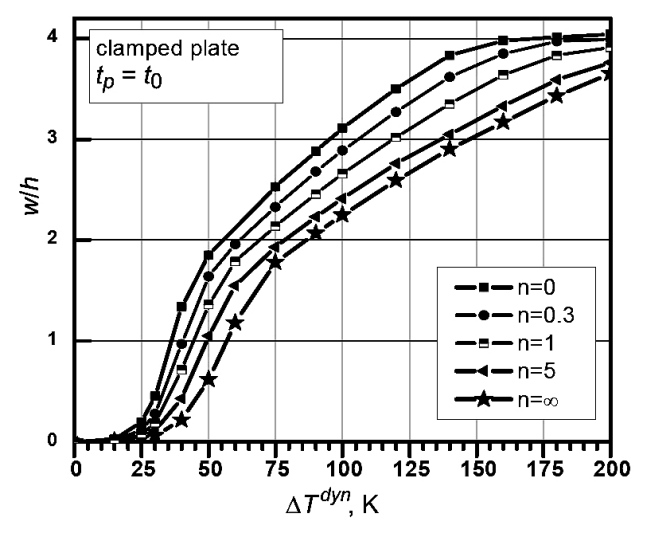

a

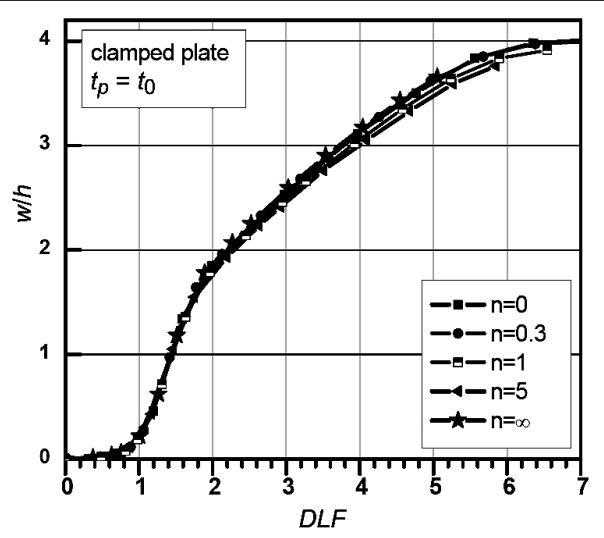

b

Fig. 4. Nondimensional maximal deflections versus pulse amplitude (a) and DLF (b) for different volume fraction index $n$ and pulse duration $t_{p}=t_{0}$ (clamped plate).

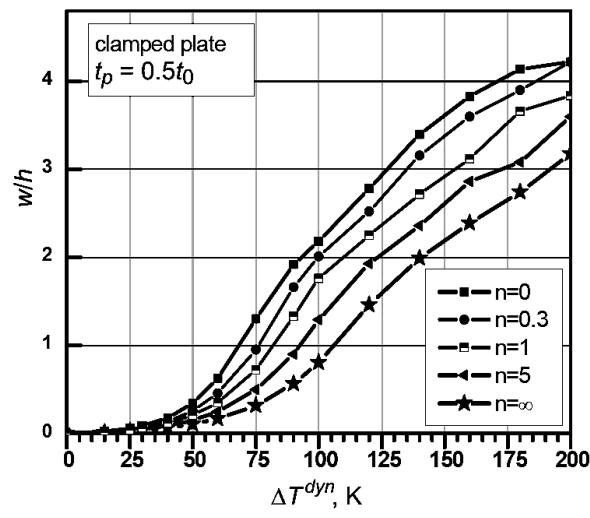

a

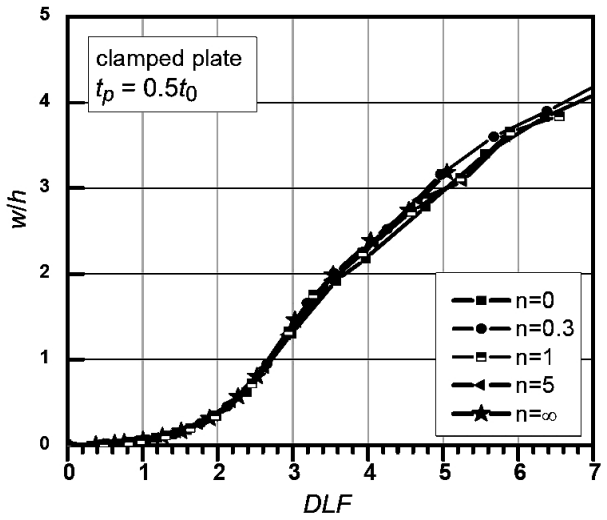

b

Fig. 5. Nondimensional maximal deflections versus pulse amplitude (a) and $D L F$ (b) for different volume fraction index $n$ and pulse duration $t_{p}=0.5 t_{0}$ (clamped plate).

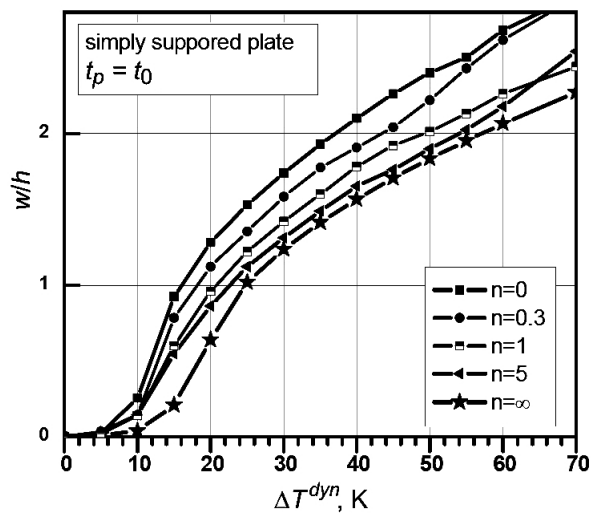

a

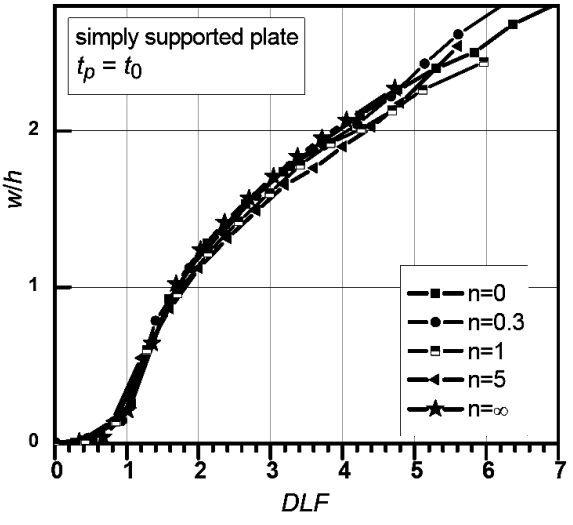

b

Fig. 6. Nondimensional maximal deflections versus pulse amplitude (a) and $D L F$ (b) for different volume fraction index $n$ and pulse duration $t_{p}=t_{0}$ (simply supported plate). 
$\mathrm{T}$ a b 1 e 4

Static and Dynamic Critical Values of Temperature Increment for $t_{p}=t_{0}$

\begin{tabular}{|c|c|c|c|c|c|c||}
\hline \multirow{2}{*}{$\begin{array}{c}\text { Volume fraction } \\
\text { index } n\end{array}$} & \multicolumn{3}{|c|}{ Clamped plate } & \multicolumn{3}{c||}{ Simply supported plate } \\
\cline { 2 - 7 } & $\Delta T_{c r}^{s t}, \mathrm{~K}$ & $\Delta T_{c r}^{d y n}, \mathrm{~K}$ & $D L F_{c r}$ & $\Delta T_{c r}^{s t}, \mathrm{~K}$ & $\Delta T_{c r}^{d y n}, \mathrm{~K}$ & $D L F_{c r}$ \\
\hline 0 & 25.18 & 36.0 & 1.43 & 9.42 & 12.0 & 1.38 \\
\hline 0.3 & 28.19 & 37.5 & 1.33 & 10.70 & 13.0 & 1.21 \\
\hline 1.0 & 30.55 & 40.0 & 1.31 & 11.72 & 13.5 & 1.15 \\
\hline 5.0 & 34.19 & 44.0 & 1.29 & 12.48 & 14.0 & 1.12 \\
\hline$\infty$ & 39.59 & 56.0 & 1.41 & 14.80 & 17.0 & 1.15 \\
\hline \hline
\end{tabular}

$\mathrm{T}$ a b 1 e 5

Static and Dynamic Critical Values of Temperature Increment for $t_{p}=0.5 t_{0}$

\begin{tabular}{|c|c|c|c|c|c|c||}
\hline \hline \multirow{2}{*}{$\begin{array}{c}\text { Volume fraction } \\
\text { index } n\end{array}$} & \multicolumn{3}{|c|}{ Clamped plate } & \multicolumn{3}{c||}{ Simply supported plate } \\
\cline { 2 - 7 } & $\Delta T_{c r}^{s t}, \mathrm{~K}$ & $\Delta T_{c r}^{d y n}, \mathrm{~K}$ & $D L F_{c r}$ & $\Delta T_{c r}^{s t}, \mathrm{~K}$ & $\Delta T_{c r}^{d y n}, \mathrm{~K}$ & $D L F_{c r}$ \\
\hline 0 & 25.18 & 67 & 2.66 & 9.42 & 32.5 & 3.45 \\
\hline 0.3 & 28.19 & 70 & 2.48 & 10.70 & - & - \\
\hline 1.0 & 30.55 & 83 & 2.71 & 11.72 & 34.0 & 2.90 \\
\hline 5.0 & 34.19 & 95 & 2.82 & 12.48 & 38.0 & 3.04 \\
\hline$\infty$ & 39.59 & 112 & 2.69 & 14.80 & 52.0 & 3.61 \\
\hline
\end{tabular}

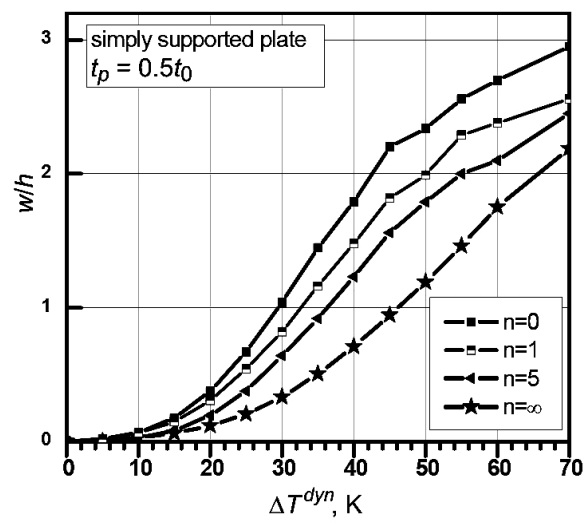

a

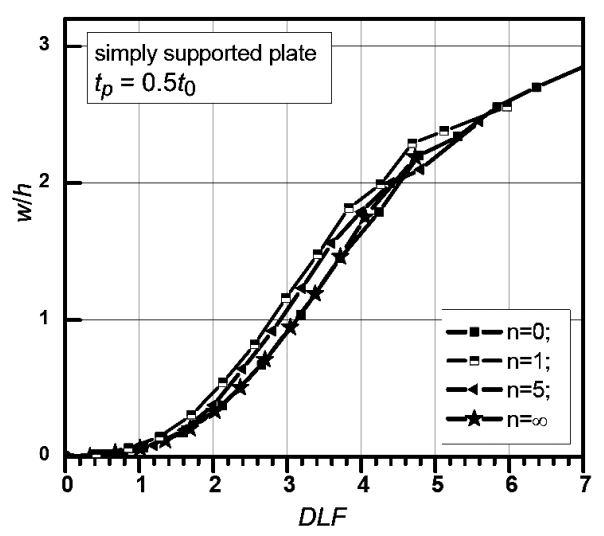

$\mathrm{b}$

Fig. 7. Nondimensional maximal deflections versus pulse amplitude (a) and $D L F$ (b) for different volume fraction index $n$ and pulse duration $t_{p}=0.5 t_{0}$ (simply supported plate).

Comparing the curves presented in Figs. 4-7 and the results shown in Tables 4 and 5 it can be noticed that:

(i) the relations $w / h=f(D L F)$ for assumed boundary conditions and temperature pulse duration are almost independent on volume fraction index $n$ (Figs. 4b, 5b, 6b, and 7b) but values of DLFcr determined on the basis of Budiansky-Hutchinson criterion differs from 10 to $15 \%$; 
(ii) for shorter pulse duration of temperature rise the character of curves $w / h=f(D L F)$ changes and the values of $D L F_{c r}$ grow up (this effect is greater in case of simply supported plates).

In Fig. 8 the comparison of dynamic responses of functionally graded plates with volume fraction index $n=1$ (it is a specific case when material properties are distributed linearly across the plate thickness - see Fig. 1) is shown. The influence of boundary conditions and pulse duration of temperature rise on the character of curves $w / h=f(D L F)$ can be easily seen. It is interesting to point out that for clamped plate for $t_{p}=0.5 t_{0}$ the deflections are much smaller than for $t_{p}=t_{0}$ (for the same value of $D L F$ ) and the curves intersect at the value $D L F \approx 6$, while for simply supported plates the curves for $t_{p}=0.5 t_{0}$ and $t_{p}=t_{0}$ stay closer and they intersect at the value of $D L F$ close to 4 .

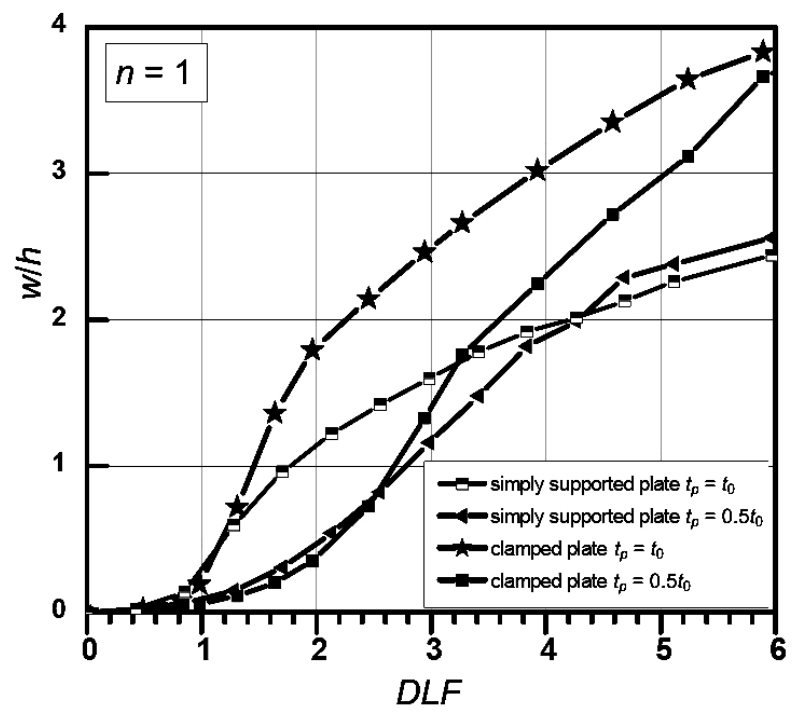

Fig. 8. Comparison of dynamic nondimensional responses for two pulse duration and two boundary conditions - volume fraction index $n=1$.

Conclusions. In this paper, the analysis of dynamic behavior of FG plates subjected to uniform temperature rise, applied dynamically as a pulse of finite duration, have been conducted. This analysis has shown that similarly as for mechanical pulse loadings the character of plate dynamic responses and dynamic critical values of temperature increment strongly depend on pulse duration and - as it is expected - on the boundary conditions. It should be marked that the considerations have been conducted under the assumption that the material properties are temperature independent and for small initial imperfection amplitude, therefore the effect of imperfection sense (towards ceramic surface or metallic surface) could be neglected. For larger values of initial imperfection amplitudes the sense of imperfection can influence the critical values of pulse temperature increment.

This study is supported by the Ministry of Science and Higher Education in Poland - National Science Center Grant No. 2011/01/B/ST8/07441. 
Р е 3 ю м е

Представлено явище втрати стійкості під час статичного і динамічного навантаження (імпульс скінченної тривалості) функціонально-градієнтних пластин за рівномірного підвищення температури. Розглянуто шарнірно оперті або закріплені (вздовж кромок) тонкі прямокутні пластини з нерухомими кромками. Припускається, що властивості матеріалу, які плавно змінюються по товщині, не залежать від температури. Проведено дослідження для різних значень коефіцієнта відносного об'єму і рівномірного приросту температури, представленого у вигляді прямокутного імпульсу скінченної тривалості.

1. J. N. Reddy, "Analysis of functionally graded plates," Int. J. Num. Meth. Eng., 47, 663-684 (2000).

2. H.-S. Shen, Functionally Graded Materials: Nonlinear Analysis of Plates and Shells, Taylor \& Francis Group, London (2009).

3. H. van Tung and N. D. Duc, "Nonlinear analysis of stability for functionally graded plates under mechanical and thermal loads," Compos. Struct., 92, 1184-1191 (2010).

4. X. Y. Lee, X. Zhao, and J. N. Reddy, "Postbuckling analysis of functionally graded plates subject to compressive and thermal loads," Comp. Meth. Appl. Mech. Eng., 199, 1645-1653 (2010).

5. T. L. Wu, K. K. Shukla, and J. H. Huang, "Post-buckling analysis of functionally graded rectangular plates," Compos. Struct., 81, 1-10 (2007).

6. M. Bodaghi and A. R. Saidi, "Levy-type solution for buckling analysis of thick functionally graded rectangular plates based on the higher-order shear reformation plate theory," Appl. Math. Model., 34, 3659-3673 (2010).

7. B. A. Samsam Shariat, R. Javaheri, and M. R. Eslami, "Buckling of imperfect functionally graded plates under in-plane compressive loading," Thin-Walled Struct., 43, 1020-1036 (2005).

8. R. Javaheri and M. R. Eslami, "Thermal buckling of functionally graded plates based on higher order theory," J. Therm. Stresses, 25, 603-625 (2002).

9. N. Kyung-Su and K. Ji-Hwan, "Thermal postbuckling investigations of functionally graded plates using 3-D finite element method," FE Anal. Design, 42, 749-756 (2006).

10. A. Tylikowski, "Dynamic stability of functionally graded plate under in-plane compression," Math. Probl. Eng., No. 4, 411-424 (2005).

11. L. Czechowski, "Dynamic stability of rectangular orthotropic plates subjected to combined in-plane pulse loading in the elasto-plastic range," Mechanics Mech. Eng., 12, No. 4, 309-321 (2008).

12. K. Kowal-Michalska, Dynamic Stability of Composite Plate Structures [in Polish], WNT, Warsaw (2007).

13. W. J. Hutchinson and B. Budiansky, "Dynamic buckling estimates," AIAA J., 4, No. 3, 525-530 (1966). 
14. K. Kowal-Michalska and R. Mania, "Static and dynamic buckling of FG plate subjected to thermomechanical loading," in: Proc. of Stability of Structures (XIII Symp.), Zakopane (2012), pp. 373-382.

15. K. Kowal-Michalska and R. Mania, "Static and dynamic buckling of FGM plates," in: M. Krolak and R. J. Mania (Eds.), Statics, Dynamics, and Stability of Structures, Vol. 1: Stability of Thin-Walled Plate Structures, Ch. 6, Lodz University of Technology (2011), pp. 131-151.

16. ANSYS 14.0. Manual. 